Aus der II. Medizinischen Klinik der Universität in München. (Direktor: Geh. Rat v. Müller.)

\title{
Bemerkungen zu C. Brucks neuesten sero-chemischen Untersuchungen.
}

Von Prof. Dr. H. Kämmerer.

Die Ergebnisse von Kämmerer ${ }^{1}$ ), Hauptmann ${ }^{2}$ ) u. a., daß die von $\mathrm{Bruck} \mathrm{k}^{3}$ ) zuerst angegebene Salpetersäurereaktion innige Beziehungen zum Gesamtglobulingehalt des Serums aufweist, haben neuerdings $\mathrm{Bruck}^{4}$ ) angeregt, sich dem Studium der Globuline im Luesserum zuzuwenden. Das Hauptergebnis seiner ausführlichen Arbeit ist - alle Einzelheiten und zum Teil erfolglosen Vorversuche sollen uns hier nicht beschäftigen -, daß $\mathrm{Br} u \mathrm{ck}$ durch seine Experimente schließlich zu einer neuen, sehr einfachen Methode geführt wird, die ihm mit der Wa.R. fast völlig übereinstimmende Resultate gibt und auch Licht auf das dunkle Wesen der Komplementbindungsreaktion bei Lues zu werfen scheint. Die Methode besteht im wesentlichen darin, daß zu 1 Stunde bei $56^{\circ}$ in. aktivierten, mit Wasser verdünnten Sera tropfenweise Milch. säureverdünnungen 1:1000 gebracht werden.

Bruck findet b9i Zusatz von ansteigenden Milchsäuremengen zu den Sera „einen linken und einen rechten Flügel der Globulinfällungszone, von denen der linke einen Maßstab für die leichtere oder schwerers Globulinfällbarkeit gebe, während der rechte approximative Werte über den Gesam tglobulingehalt des betreffenden Serums anzeige." Zu seiner neuen Reaktion benützt $\mathrm{Br}$ uck den rechten Flügel, d. h., er stellt den Verdünnungsgrad fest, bei dem durch die Milchsäure innerhalb einer Stunde bei Zimmertemperatur eben Ausflockung eintritt. Die Methode, deren Einzelheiten im Original nachzulesen sind, stimmte bei 60 Sera mit der Wa.R. völlig üborein.

Ueber die praktische Bedeutung der neuen Probe will ich mir hier kein Urteil crlauben; aber nach der Lektüre der Bruckschen Arbeit erschien es mir zweckmäßig, ihre theoretischen Voraussetzungen und Beziehungen zu einigen früheren Forschungsergebnissen etwas näher zu erörtern und kritisch zu beleuchten; vielleicht konnten dadurch für weitere Studien auf diesem Gebicte einige brauchbaren Gesichtspunkte geliefert werden.

Bruck fällt also bei seiner neuen Methode aus verdünnten, auf $56^{\circ}$ erhitzten Sera durch Zusatz geringer Säuremengen Eiweißkörper aus. Die ersten Feststellungen in dieser Hinsicht liegen schon 15 Jahre zurück und stammen von Die ud on n é ${ }^{\mathbf{1}}$ ), der in Serumverdünnungen (1:10 mit Aqu. dest.), die einerseits inaktiviert, ja zum Teil nur auf $45^{\circ}$ erhitzt, anderseits aktiv waren, Bacterium coli einsäte. In den erhitzten Sera erhielt er - offenbar durch die Säurebildung der Kolikultur jedesmal eine mehr oder weniger starke Eiweißfällung, in den aktiven nicht. Mit der theoretischen Bedeutung und etwaigen praktischen Verwendbarkeit der Di e u d on néschen Beobachtung beschäftigt, war ich sehr überrascht, in der letzten Bruckschen Arbeit einen im Prinzip so ähnlichen Vorgang tatsächlich zu einer praktischen sero-chemischen Methode benutzt zu finden. Zunächst ist allerdings auffallend, daß Bruck durch die Inaktivierung eine Verminderung, Dieudonn é eine Vermehrung der Eiweißfällbarkeit durch Säurewirkung feststellt. Auf diesen scheinbaren Widerspruch wird weiter unten zurückzukommen sein.

Zum Verständnis des Kommenden müssen folgende aus der Eiweißchemie bekannten Sätze ${ }^{5}$ ) vorausgeschickt werden:

1) M. m. W. 1917 Nr. 8. ${ }^{2}$ ) D. m. W. 1917 Nr. 16. - ${ }^{3}$ ) M. m. W. 1917 Nr. 1. - 4) M. m. W. 1917 Nr. 35 u. 36. - 5) Hyg. Rundsch, 1902 Nr. 18, 
1. Denaturierung der Eiweißkörper durch Erhitzung tritt bei jeder Reaktion mit oder olne Salze ein, aber die Schicksale des denaturierten Eiweißes sind verschieden. 2. Denaturiertes Eiweiß ist in Wasser und neutralen Salzlösungen unlöslich, löslich in Säuren und Alkalien durch Bildung von Säure- und Alkalialbuminat. 3. Ganz reine, salzfreie Eiweißlösung fällt beim Erhitzen sofort aus, es bleibt nichts in Lösung. 4. Zusatz eines Tropfens verdünnter Säure oder verdünnten Alkalis verhindert die Koagulation völlig. 5. Spur eines Salzes genügt zur Fällıng bel sauerer Lösung, zur Fällung bei alkalischer Lösung ist mehr Salz notwendig.

Zur Erklärung des Dieudonneschen Phänomens, das schon Cohnheim ${ }^{1}$ ) mit der Alkalialbuminatbildung in Zusammenhang brachte, kam ich nach mancherlei Versuchen und Ueberlegungen zu folgender Anschauung: Durch die Erhitzung der Serumverdünnung wird das Serumeiweiß denaturiert. Das denaturierte Eiweiß bildet mit dem Alkali des Serums lösliches Alkalialbuminat, Koagulation tritt nicht ein, da zu wenig Salze da sind. Kommt nun eine geringe Säuremenge zu der Serumverdünnung, so bildet die Säure mit dem Alkali des Serums zunächst ein Salz. Schon eine sehr geringe Säuremenge genügt aber, um bei saurer Reaktion Ausfällung des Eiweißes zu bewirken. Kommt also weiterhin Säure (d. h. bis zu saurer Reaktion der Serumverdünnung) hinzu, so koaguliert das denaturierte Eiweiß. Die bakterielle Säurebildung liefert offenbar gerade die richtige Säuremenge. In aktiven Sera tritt die Erscheinung nicht oder nur in Spuren ein, da hier denaturiertes Eiweiß nur in Spuren vorhanden ist.

Ueber den erwähnten Widerspruch und manches andere bringen besonders die Untersuchungen von Sachs und Alt$\operatorname{man} n^{2}$ ) einiges Licht. Sie gingen aus von der bekannten Kla us nerschen Serumreaktion mit destilliertem Wasser. Nach ihren Untersuchungen verschwindet die Klausnersche Reaktion oder nimmt ab bei der Erhitzung auf 56 ${ }^{\circ}$ Dies stand in scheinbarem Widerspruch mit den Feststellungen von Moll ${ }^{3}$ ), der nach Serumerhitzung auf $56^{\circ}$ eine Vermehrung der Globuline, auf $60^{\circ}$ Alkalial buminatbildung und damit Vermehrung des Niederschlags durch Säuerung feststellte. Nun hatten aber L. und P. v. Liebermann ${ }^{4}$ ) schon 1907 gefunden, dab die Alkalinität des Serums unter dem Einfluß der Erwärmung auf $56^{\circ}$ zunimmt (was Bruck entgangen zu sein scheint, da er die Tatsache jetzt durch ausführliche Versuche zu beweisen sucht). Ferner hatten Elias, Porges, Neubauer und Salomon ${ }^{5}$ ) festgestellt, daß zur Globulinausflockung nach Kla u s ner eine bestimmte optimale Azidität notwendig sei. Da also das Verschwinden der Klausnerschen Reaktion bei der Inaktivierung offenbar mit der Alkalinitätszunahme zusammenhing, setzten Sachs und Altmann zu den inaktivierten Sera Säure. Es ergab sich, daß solche Sera wieder ,Klausner positiv“" wurden. Umgekehrt konnten Klausner-positive Sera durch Alkalizusatz negativ gemacht werden. Die Autoren setzten dann zu Serumverdünnungen stufenweise Säure - von $1 / 1000 \mathrm{n}$ bis $1 / 500 \mathrm{n}$ Salzsäure - zu und fanden: nach Erhitzung des Serums auf $56^{\circ}$ setzt der Beginn der Niederschlagsbildung erst bei eilıer größeren Säuremenge ein als beim aktiven Serum. Bei weiterem Säurezusatz tritt beim aktiven wie beim inaktiven Serum Vermehrung des Niederschlags ein bis zu einem Optimum, dann erfolgt Lösung der Niederschläge. Der maximale Niederschlag bildet sich beim aktiven Serum ungefähr beim gleichen Säuregrad wie beim inaktivierten, ist aber bei letzterem konstant viel stärker als bei ersterem.

So löst sich der scheinbare Widerspruch zwischen den Ergebnissen von Sachs - Altmann und Moll. Ich glaube, wir dürfen diesen Versuch aber auch ruhig zur Erklärung des oben erwähnten Widerspruchs zwischen den Dieudon n é schen und Bruckschen Versuchsergebnissen heranziehen. Das schon im Jahre 1908 von Sachs und Alt ma n n publizierte Experiment Inaktivieren der Sera auf $\tilde{5} 6^{\circ}$ und Eiweibfällung durch stufenweisen Zusatz stark verdünnter Säure zu wäßrigen Serumlösungen - ist nun meines Erachtens im Prinzip durch nichts verschieden von der jetzt von Bruck ange-

1) Nach Cohnheim, Chemie d. Eiweißkörper. — 2) Cit. nach Sachs, Sémaine méd. Juni 1908. - ${ }^{3}$ ) Beitr. z. chem. Phys. u. Path. VI. 1904. - 4) Arch. f. Hyg. 62. - 5) W. klin. W. 1908 s. 376. gebellen Versuchsanordnung. Erstere Autoren betollen jedoch ausdriicklich, daß diese Probe fiir die praktische Syphilisdiagnose keine Vorteile biete, dab sich grole Differenzen gezeigt hätten. Bruck hat gute praktische Resultate; sollte das an der Verwendung von Milchsäure statt Salzsäure liegen? Ein solcher Unterschied erscheint mir zweifelhaft, ist jedoch nicht unmöglich. Vergleichende Versuche über die Fällungszonen verschiedener Säuren bei verschiedenen Serumlösungen müßten vorgenommen werden.

Auf die Inaktivierung legt Bruck besonderen Wert, da er auf Grund seiner Ergebnisse annimmt, daß durch die Erhitzung eine im frischen Serum vorhandene Säure abgeschwächt bzw. verflüchtigt wird. Dadurch glaubt er deı Säuregehalt des Serums fast bzw. völlig zul beseitigen und so eme Fehlerquelle auszuschalten. Zehn Jahre vorher haben nun schon L. und P. Lieberman $n^{1}$ ) über diesen Punkt Versuche angestellt. Frisches Serum ist nach allgemeiner Nomenklatur bekanntlich nicht sauer, sondern alkalisch, weshalb auch L. und P. Liebermann wohl mit Recht nicht von einer Abnahme der Säure, sondern von einer Zunahme der Alkalinität sprechen, vou ihnen nachgewiesen durch die Steigerung der Hydroxylionenkonzentration. (Die Menge des titrierbaren Alkalis erfuhr übrigens bei ihnen im Gegensatz zu Bruck durch Inaktivieren keine Aenderung.) Die Vorstellung Brucks, daß durch die Erhitzung und Verflüchtıgung von Säuren sich sozusagen eine konstante Reaktion der Sera erzielen lasse, ist wohl sicher nicht richtig. Schon aus den Versuchszahlen von $L$. und P. Liebermann ist zu ersehen, daß die Hydroxylionenkonzentration nach der Erhitzung sich zwar geändert hat, aber bei den einzelnen Sera gerade so verschieden ist wie vorher auch, wie das ja auch wahrscheinlich ist. Da aber die Eiweißfällbarkeit durch Alkalizusatz herabgesetzt werden kann, so hängt auch nach dem Inaktivieren die Fällbarkeit wohl ziemlich ausschließlich von der Hydroxylionenkonzentration, von dem erreichten Alkalinitätsgrad ab, der durch das Illaktivieren bei den einzelnen Sera recht verschieden ansfallen dürfte, besonders, da bei pathologischen Zuständeı schon die aktiven Sera ziemlich große Differenzen zeigen.

Bis auf weiteres glaube ich, daß die oben angeführten, aus der Eiweißchemie bekannten Sätze hinreichen, eine einfache Erklärung sowohl für das Dieudonn é sche Phänomen als für die Sachs-Altmannschen und schließlich auch die Bruckschen Säureversuche zu liefern. Sie ließe sich etwa folgendermaßen formulieren: Durch das Inaktivieren auf $56^{\circ}$ wird eill Teil des Serumeiweißes denaturiert, gleichzeitig nimmt die Serumalkalinität zu. Das denaturierte Eiweiß verbindet sich mit dem Serumalkali zu Alkalialbuminat. Durch den Zusatz. der Säure entsteht zunächst mit dem Serumalkali Salz. Sobald bei weiterem Säurezusatz saure Reaktion eintritt, fällt das denaturierte Eiweiß infolge der Gegenwart des Salzes aus. Der Eintritt dieser Eiweißfällung hängt von der Alkalinität, der Hydroxylionenkonzentration, des Serums ab. Da auch im aktiven Serum eine mehr oder weniger geringe Menge denaturierten Eiweißes sich befindet, so geben auch Verdünuungen solchen Serums mit verdünnter Säure einen, allerdings viel unbedeutenderen, Niederschlag. Wegen der geringeren Alkalinität des aktiven Serums tritt die Fällung schon bei geringerem Säurezusatz ein. - Es wäre jedenfalls eine sehr interessante Beob. achtung Brucks, wenn der Milchsäure oder sonstigen organischen Säuren als Fällungsmitteln engere, spezifischere Grenzen gezogen wären.

Bezüglich des Vorhandenseins von denaturiertem Eiweiß in nicht erhitztem, sogen. aktivem Serum erscheinen mir die erwähnten Dieudonné schen Untersuchungen ganz besonders bemerkenswert. Aus seinen Koliversuchen geht hervor, daß eine Denaturierung sich schon durch Erhitzung der Sera auf nur $45^{\circ}$ nachweisen läßt. Wie nahe liegt dieso Temperatur den höchist beobachteten Fiebergraden! Unter dem kombinierten Einfluß von Krankheitsgiften und bohen Temperaturen, die längere Zeit einwirken, ist eine teilweise Denaturierung des Plasmaeiweißes garnicht undenkbar. Aucli Sachs ${ }^{1}$ ) spricht von einer Denaturierung des Serumeiweißes durch die Syphilis.

l) $1 . \mathrm{c}$. 
Ist die nenc Brucksche Reaktion wirklich in die gleiche Kategorie mit dell angeführten Fällungsphänomenen von Die u donné und Sachs-Altmann zu stellen, ist die gegebene Erklärung zutreffend, so ist unwahrscheinlich, daß sie mit dem Wesen der Wa.R. in innigstem Zusammenhang steht. Auch sie hat dann wieder nur nahe Beziehungen zu der viel weniger spezifischen Klausnerschen Reaktion wie Brucks erste Versuchsanordnung. Ich glaube vorderhand nicht, daß die Säureverhältnisse und die Globulinfällbarkeit, wie Bruck meint, der wesentlichste Punkt bei der Wa.R. sind, wenigstens nicht die Globulinfällbarkeit infolge der Säureverhältnisse. Die größere Spezifizität der Wa.R. verlangt doch wohl besondere Eigenschaften des Serumglobulins. Bedeutungsvoll dürfte hier auch das Ergebnis von Sachs ${ }^{1}$ ) sein, daB es nicht gelingt, ein nicht syphilitisches Serum durch Hinzufügen von Säure Wassermann-positiv zu machen. Man sollte erwarten, daß es mit Milchsäure gelingt, wenn der neuen Bruckschen Reaktion wirklich eine syphilisspezifische Bedeutung zukommt.

Abgeschlossen 7. X. 17 . 